\title{
GLAZING EDGE-SEAL USING FOAMGLASS AS SPACER AND FRAMELESS WINDOW DESIGN
}

\author{
MICHAEL LÖFFLER and DORIS BUCK \\ Universität Karlsruhe, Institut für Industrielle Bauproduktion, \\ Lehrbereich Bauphysik und Technischer Ausbau, Englerstr. 7, D-76128 Karlsruhe, Germany
}

Received 7 January 1997; revised version accepted 10 July 1997

\author{
Communicated by VOLKER WITTER
}

\begin{abstract}
This article presents a new design for the edge-seal of multiple-glazings with spacers made of foamglass and a new concept for frameless windows to reduce the heat loss through windows significantly. Thus the energy demand for heating is reduced or covered by solar energy gains through the window to a higher extent. The thermal performance of window assemblies with foamglass spacers and with and without frames is compared with that of the common window design. For the calculations of the heat flux a finite element analysis computer program has been used to account for the 2D-effects in the glazing, edge-seal and frame heat transfer patterns. The total heat transfer through an example window with a glazing $1 \mathrm{~m} \times 1 \mathrm{~m}$ is reduced by $45 \%$ using the window design presented. The objective of this article is not only to quantify the heat fluxes for different combinations of glazing, edge-seal and frame. The major part of the article focuses on practical aspects that are important for the durability of edge-seals, such as mechanical stress within the materials, water vapour and gas tightness, as well as on new design concepts of window-wall joints. A frameless window construction is an important aspect to enhance the thermal performance of windows. The costs for this kind of frameless windows are estimated to be less than or equal to windows commonly used now. (C) 1997 Published by Elsevier Science Ltd.
\end{abstract}

\section{NOMENCLATURE}

$A_{\mathrm{G}} \quad$ area of glazing $\left(\mathrm{m}^{2}\right)$

$A$ total area of window including edge-seal or frame $\left(\mathrm{m}^{2}\right)$

$b$ width of panes $(\mathrm{m})$

$d$ thickness of panes (m)

$E_{\mathrm{G}}$ elastic modulus of glass $\left(\mathrm{N} / \mathrm{mm}^{2}\right)$

$E_{\mathrm{K}}$ elastic modulus of sealant $\left(\mathrm{N} / \mathrm{mm}^{2}\right)$

$h(q)$ average distance of the panes $(\mathrm{m})$

$h_{0}$ distance of the panes without mechanical load, equal to the height of the spacer $(\mathrm{m})$

$J$ area moment of inertia of panes $\left(\mathrm{m}^{4}\right)$

$k$ gluing width $=$ width of the spacer (m)

$l$ length of panes (m)

$L$ length of all edges $(\mathrm{m})$

$p_{\text {in }} \quad$ pressure of gas between the panes $(\mathrm{Pa})$

$p_{\text {out }} \quad$ weather-dependent pressure of ambient air $(\mathrm{Pa})$

$q$ pressure load $(\mathrm{Pa})$

$\Delta T$ temperature difference between indoor and ambient air $(\mathrm{K})$

$U_{\mathrm{G}}$ centre-of-pane $U$ value $\left(\mathrm{W} /\left(\mathrm{m}^{2} \mathrm{~K}\right)\right)$

$U_{\text {eq }}$ equivalent $U$ value $\left(\mathrm{W} /\left(\mathrm{m}^{2} \mathrm{~K}\right)\right)$

$w$ displacement $(\mathrm{m})$

$X_{\mathrm{E}}$ length-dependent heat flux coefficient $(\mathrm{W} /(\mathrm{m} \mathrm{K}))$

\section{Greek letters}

$\varphi$ gluing-angle (deg)

$\Delta \varphi$ bending angle (deg)

$\Phi$ total heat flux $\left(\mathrm{W} / \mathrm{m}^{2}\right)$

$\xi$ length variable $(0 \ldots 1)$ (dimensionless)

\section{INTRODUCTION}

The northern industrial countries consume most of the fossil energy consumed at present. The production of low energy temperature for the heating of buildings causes a major part of the energy consumption and the $\mathrm{CO}_{2}$ emissions in these countries. Concerning the energy demand for heating, the construction of windows is important in two respects: on the one hand window areas increase the heat loss because of their bad insulation coefficient; on the other hand the transparency of windows results in the gain of solar energy. Using windows with low $U$ values, the gain of solar energy can exceed the heat loss. In this case the windows turn into solar collectors. The aim of this article is to discuss two window details that significantly reduce the $U$ value.

Many improvements in glazing systems have been achieved within the last decades, such as low-emissivity coatings and gas fills of insulation glass units. These reduce the heat loss through the glazing. However, the edge-seal of insulation glass units containing metal spacers are thermally highly conductive and act as a thermal short-circuit.

Another weak point in window design is the frame, particularly metal frames. However, wooden or PVC frames also have $U$ values higher than modern well-insulating glazings. To improve the thermal performance of metal frames, nowadays these are produced with a thermal break of plastic material or with polyurethane foam fills of the cavities. Frames 
consisting of polyurethane foam with a metal reinforcement bar (Feist, 1996) are still in the experimental state.

\section{EDGE-SEAL AND WINDOW-WALL JOINT DESIGN}

Substituting the aluminium spacers by spacers made of low-conductivity material reduces the heat loss through the edge-of-pane area of the window. Spacers of plastic and of silicone foam have been developed and investigated regarding their thermal properties. This included measurements as well as calculations that were compared with the measurements for evaluation (Wright and Sullivan, 1989; Elmahdy and Frank, 1993; Ghazi Wakili and Frank, 1993; Wright et al., 1994; Aschehoug and Baker, 1995; Frank and Ghazi Wakili, 1995; Sullivan and Wright, 1995; Van Dijk, 1995). The calculation program was tested regarding the effect of the degree of accuracy of the input data on the results obtained (Fraser et al., 1993; Reilly, 1994). McGowan (1995) refined the calculation procedure to accomplish better agreement with measured data.

In Germany, plastic spacer materials have been investigated regarding their vapour and gas diffusion resistance and their compatibility with gluing materials. Despite their good thermal properties, there are still great unsolved problems of gas diffusion and mechanical stability of the edge-seal (BMBF, 1996).

However, using foamglass as spacer material (Canmet and Fritzel, 1995) could solve these problems. From the energetical point of view foamglass exceeds these spacer materials by its lower thermal conductivity, which is a factor of 100 lower than that of an aluminium spacer and a factor of three lower than that of a foam spacer investigated by Wright and Sullivan, 1989. Also, foamglass allows for omitting the secondary seal and thus for reducing the thermal conductivity of the entire edge-seal to the very low value of foamglass.

Taking the physical properties of foamglass and the sealant materials into account, a new design of the spacer cross-section and the choice of the sealant has to be found to assure mechanical stability of the glazing as well as low thermal conductance.

Even further reductions of heat loss can be obtained by omitting the window frame and using frameless glazings. Frameless glazings are used as structural glazing in industrial and office buildings, but with the new design they can also be used like common windows in residential buildings. In both cases the integration into the façade has to avoid thermal bridges to benefit from the low conductance of the glazing and edge-seal.

This section summarizes the results presented in two German publications (Löffler, 1995;Löffler, 1996).

\subsection{Characteristics of foamglass}

Foamglass is produced in different types with varying physical properties. Some values are given in Table 1 (Pittsburgh, 1992). The values with question marks are calculated (proportional to pressure resistance) and added by the author. In general, foamglass has very low thermal conductivity, but a relatively high pressure resistance. Therefore, it is used as thermal insulation material where some mechanical stability is required. On the other hand, its tensile strength is much lower. Foamglass is vapourand gas-proof, which is an important property for using it as spacer material for glazings. As it is glass it is compatible with the commonly used sealant materials. Foamglass can be worked with ordinary methods, e.g. sawn to produce the spacer sticks from foamglass blocks. These characteristics have to be taken into account when designing the structure of the edge-seal and choosing the sealant materials.

\subsection{Pressure load on glass panes and spacers}

To show that foamglass can stand the loads occurring, first the maximum mechanical loads on the panes will be summed up. These loads arise from different sources:

- weather-dependent change of air pressure $\pm 60 \mathrm{hPa}$;

- temperature change of the gas fill $\pm 40 \mathrm{~K}$;

- the wind load affects both panes, so the load on the spacer is small and not taken into account;

- altitude difference of production and use of the window (not used for the calculations) $12.2 \mathrm{hPa} / 100 \mathrm{~m}$

Glazings used in altitudes much different from the production altitude have to be treated specially (pressure adjustment to the local environment)

\subsection{Bend curve and gas pressure}

The under- or overpressure in the gas-filled cavity between the panes leads to a bending of the glass panes. For the following calculations 
Table 1. Physical properties of foamglass

\begin{tabular}{lcccc}
\hline & \multicolumn{4}{c}{ Foamglass type } \\
\cline { 2 - 5 } Characteristic & T4-040 & T4 & T2 & F \\
\hline Density $\left(\mathrm{kg} / \mathrm{m}^{3}\right)$ & 110 & 120 & 125 & 165 \\
Thermal conductivity $(\mathrm{W} /(\mathrm{m} \mathrm{K}))$ & 0.04 & 0.045 & 0.05 & 0.055 \\
Pressure stability $\left(\mathrm{N} / \mathrm{mm}^{2}\right)$ & 0.65 & 0.85 & 0.9 & 1.7 \\
Tensile strength $\left(\mathrm{N} / \mathrm{mm}^{2}\right)$ & $0.18 ?$ & 0.24 & $0.25 ?$ & $0.48 ?$ \\
Elastic coefficient $\left(\mathrm{N} / \mathrm{mm}^{2}\right)$ & $53-58$ & 65 & 75 & \\
\hline
\end{tabular}

it is assumed that only two opposite spacers of the glazing take the load. The panes bend according to (Schnell et al., 1985)

$$
\text { bending curve: } w=\frac{q b l^{4}}{24 E_{\mathrm{G}} J}\left(\xi-2 \xi^{3}+\xi^{4}\right) \text {. }
$$

The increase of the air volume between the panes is related to the change of the gas pressure. The change of the volume is described by the integral of the bending curve, in the following called the bend area:

$$
\begin{aligned}
& \text { bend area: } A_{\mathbf{k}}=\int_{0}^{1} w(\xi) \mathrm{d} \xi=\frac{q b l^{5}}{24 E J} \\
& \times\left[\frac{1}{2} \xi^{2}-\frac{2}{4} \xi^{4}+\frac{1}{5} \xi^{5}\right]_{0}^{1}=\frac{q b l 5}{120 E J} .
\end{aligned}
$$

The average value of pane bending is $A_{\mathrm{k}} / l$. Both panes are bending, so the factor of two in eqn (3)(I) is necessary.

In the air- or gas-layer the gas rule is to be used: $p V=m R T$. The area of the panes remains equal so $V$ can be replaced by $A h(q)$. Therefore, $p h / T$ is constant (eqn(3)(II)). The resulting equation system is

$$
\begin{array}{cc}
\text { I: } \quad h(q)=h_{0}+2 A_{\mathbf{k}} / l=h_{0}+2 \frac{q b l^{4}}{120 E J} \\
\text { with } J=b d^{3} / 12 \\
\text { II: } \quad h(q)=\frac{h_{0} p_{0} T}{T_{0}\left(\Delta p_{\text {in }}+p_{0}\right)}
\end{array}
$$

Solving this equation system leads to the pressure between the panes and the value for $h(q)$.

As an extreme example for the overpressure between the panes, the ambient pressure was assumed to fall by $60 \mathrm{mbar}$, and the gas temperature $T$ between the panes to rise from $20^{\circ} \mathrm{C}$ to $60^{\circ} \mathrm{C}$. With panes $l=1 \mathrm{~m}$ wide and $d=4 \mathrm{~mm}$ thick and the gas layer $h_{0}=20 \mathrm{~mm}$ thick the overpressure between the panes is about 10 mbar. If only the spacers on the two opposite sides of the glazing take the load the tensional stress on spacers $10 \mathrm{~mm}$ wide is $50000 \mathrm{~N} / \mathrm{m}^{2}$ and can easily be taken by any type of foamglass.

\subsection{Angle of the interstice between spacer and panes}

The tensional stress calculated above occurs if the forces distribute evenly over the width of the foamglass spacers. To achieve this the spacers should be given a trapezoid-shaped crosssection. Figure 1 shows an edge-seal of a double glazing with foamglass spacer. The figure is not true-to-scale. Special attention is paid to the angle of the gluing-interstices between the foamglass spacer (3) and the panes (1). It will be shown that if the gluing-angle is set to a certain value the forces on the spacers are distributed evenly throughout the foamglass cross-section for any bending angle. Figure 2 shows the gluing-angle between spacer (3) and glass (1) with bending of the panes. It is necessary to prove this statement, since foamglass can stand

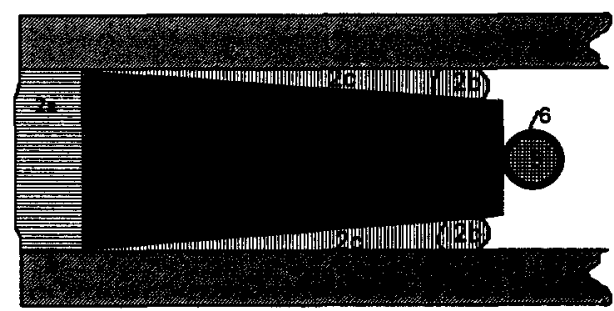

Fig. 1. Edge with foamglass: (1) glass; (2a) glue; (2b) sealant; (2c) glue or sealant; (3) foamglass spacer; (5) drying agent; (6) container for drying agent, e.g. perforated aluminium pipe.

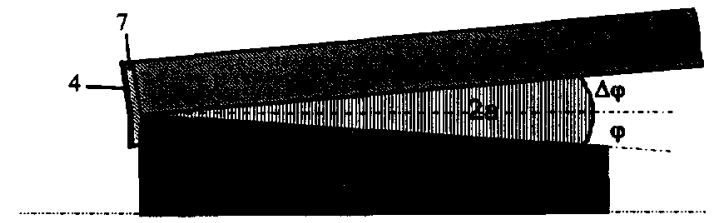

Fig. 2. Edge with bending of the pane: (1) glass; (2a) glue; (3) foamglass spacer; (4) metal foil; (7) sealant with gluing ability for the metal-glass connection. 
high pressure but it cannot stand high tensional stress. To obtain an even distribution of the tensional stress over the width of the spacer the ratio $\Delta \varphi / \varphi$ must be independent of the location within the gluing-interstice.

$$
\begin{array}{ll}
\text { Bending angle: } & \Delta \varphi=\frac{q l^{3} b}{24 E_{\mathrm{G}} J_{\mathrm{G}}} ; \quad J_{\mathrm{G}}=\frac{b d^{3}}{12} \\
E_{K} \frac{\Delta l}{l}=E_{\mathrm{K}} \frac{\Delta \varphi}{\varphi}=\frac{q l b}{2 k b}=\frac{q l}{2 k}
\end{array}
$$

From these equations the gluing-angle results as

$$
\varphi=\frac{E_{\mathrm{K}}}{E_{\mathrm{G}}} \frac{l k}{d^{3}}
$$

Result: the cross-section of the foamglass spacer must be trapezoid-shaped, so that triangle interstices (2c) for gluing result. The ideal gluingangle depends on the dimensions of the glazing.

With this form of the spacer the foamglass can stand the tensional stress that occurs. So the secondary seal (2a) is not necessary any more for keeping the glass panes together. This is an advantage since the polysulphide sealant has a much higher thermal conductivity than foamglass.

Further theoretical investigations of the stress occurring near the glazing corners and tests with sample glazings are planned for the near future. The next step could be the investigation of dynamic pressure loads (e.g. sonic boom, thunder, knocking or hitting the window).

\subsection{Diffusion of gas through the edge sealant}

For the reduction of convection and heat conduction in highly insulating windows a special insulation gas is used between the panes. Therefore, it is necessary that the edge-seal is gas proof. Foamglass is gas and vapour proof. The diffusion of gas through the gluing-interstices must be avoided, so that on the one hand the insulating gas remains between the panes and on the other hand vapour does not enter the gas-filled cavity; otherwise condensation might occur. Figure 2 shows a possibility of how to avoid the problems mentioned of diffusion through the interstice.

The concept of Fig. 2 includes the necessity to optimize the gap between the two metal foils. On the one hand, too small a gap increases the heat losses (thermal bridge effect); on the other hand, too large a gap increases the diffusion rate through the sealant.

\subsection{Frameless windows}

For glazings with foamglass spacers the frame increases the heat loss. In this case the frame is the worst insulating part. This result leads to the new concept of windows without frames. To provide the window with enough mechanical stability one pane is thicker than usual, depending on the size of the window. Figure 3Fig. 4 show the integration of a frameless glazing into the building wall.

The air-tightness of the window is assured by the sealants all around the window. The edges of the glazing can be painted or covered to hide the foamglass spacer. The narrow metal frame can be painted in any desired colour or covered, i.e. with wood. There is a wide variety of possibilities to meet any desires.

Estimating the costs in comparison with common windows one can imagine them to be similar or even lower. On the one hand,the metal frame needs less and geometrically simpler parts than common window frames, and the integration of the glazing into the casement frame is not necessary. On the other hand, the production of the special double glazing with foamglass spacers is still more time-consuming and expensive than the production of a common glazing. The integration into the building, whether new or old one, is comparable with the common way.

\section{HEAT TRANSFER THROUGH EDGE-SEAL AND TOTAL WINDOW $U$ VALUE}

To determine the total heat loss through a window it is necessary to account for the energy loss through the panes and the frame, and also for the amount of heat conducted through the inner pane toward the spacer and through the outer pane to the environment. With aluminium or other metal spacers this effect leads to an increase of energy loss. To quantify the heat loss through the different parts of the window, a finite element analysis program (Quickfield, 1995) was used to examine the heat loss through four types of example window. Quickfield is a two-dimensional program including automatic generation of a triangle grid. The grid depends on the geometry of the model and the element edge length, which can be defined by the user. Experience shows that the results obtained for the heat flux patterns and total heat fluxes vary only little with changes in the grid.

Each of the example windows has a transparent glazing area $1 \mathrm{~m} \times 1 \mathrm{~m}$ with a centre-of-pane 


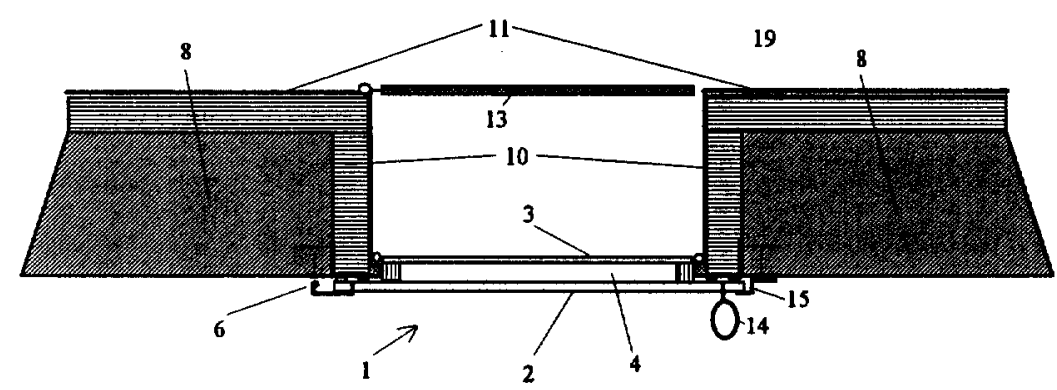

Fig. 3. Cross-section through a frameless glazing with two panes: (1) glazing; (2) pane for load; (3) pane for insulation; (4) interpane cavity; (6) fulcrum; (8) house wall; (10) house insulation; (11) plaster; (13) sun protection; (14) handle; (15) bolt; (19) environment.

$U$ value of $1.1 \mathrm{~W} /\left(\mathrm{m}^{2} \mathrm{~K}\right)$. The $U$ value of the insulated wall is $0.3 \mathrm{~W} /\left(\mathrm{m}^{2} \mathrm{~K}\right)$. The indoor and ambient temperatures are set to $20^{\circ} \mathrm{C}$ and $-20^{\circ} \mathrm{C}$ respectively. Figure $5-9$ show the temperature distribution and the isotherm lines within the cross-section of different window types. Figures 6 and 7 also show the heat flux density vectors. The heat flux is perpendicular to the isotherm lines. In Figs. 5 and 6 the heat flux within the glass panes towards the spacer and from the spacer to the environment is shown. In Fig. 8 this effect is negligible, but still the frame increases the heat loss compared with the glazing itself.

Figures 8 and 9 show frameless glazings attached to the brick wall at its inner and outer rim. The glazing in Fig. 9 continues the thermal insulation of the wall and, therefore, represents a better solution (see also Schultz and Thomsen (1990)). Note the surface temperatures of the wall, frame and glazing. With aluminium spacers the surface temperature drops to $1^{\circ} \mathrm{C}$ at the interface of glazing and frame. Condensation of water occurs, causing damage to the frame material. With foamglass spacers the inner surface temperature does not drop below $12^{\circ} \mathrm{C}$. Condensation does not occur. At the frameless window the lowest inner surface temperature is $14^{\circ} \mathrm{C}$, even at the low outside temperature chosen. The higher surface temperatures with foamglass spacers not only prevent draughts and condensation, which is particularly important for indoor swimming pools with high temperatures and humidity of the indoor air, the radiation temperature in the room, particularly near the window, is also higher and more comfortable.

However, the main advantage of the new window design is the great reduction of heat loss through the window edge-seal and frame where applicable. High inner surface temperatures are an indicator for low heat loss. The quantification was done with integrations of the heat flux densities inside the window. The total heat flux was separated into one part through the glazing, according to its $U$ value, and
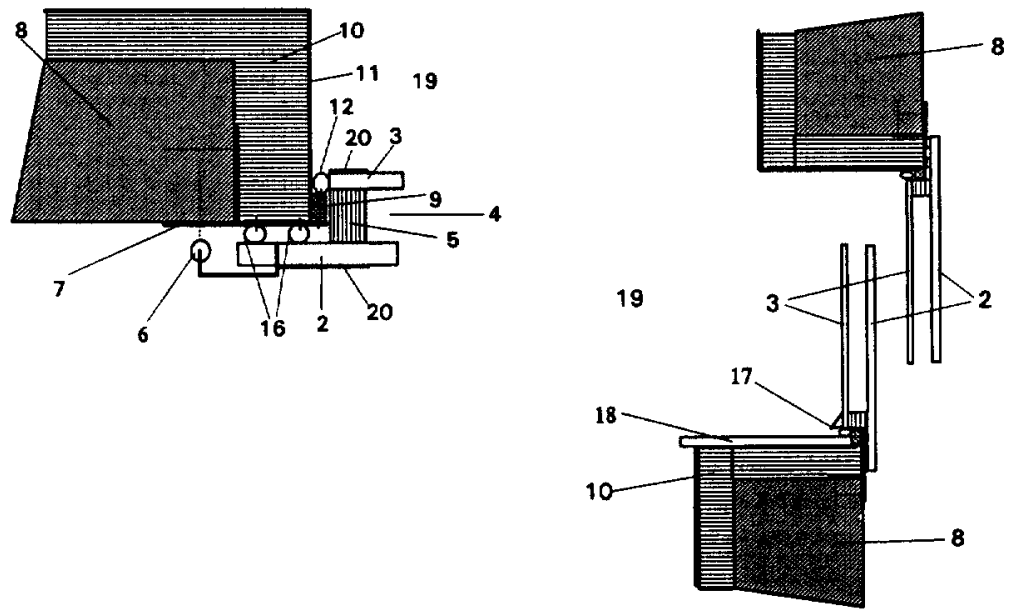

Fig. 4. Detail of the connection to the wall at the fulcrum (left) and at the top and bottom (right): (2) pane for load; (3) pane for insulation; (4) interpane cavity; (5) spacer; (6) fulcrum; (7) metal frame; (8) house wall; (9) profile; (10) house insulation; (11) plaster; (12) sealant; (16) sealant; (17) water rejection; (18) windowsill; (19) environment; (20) colour. 


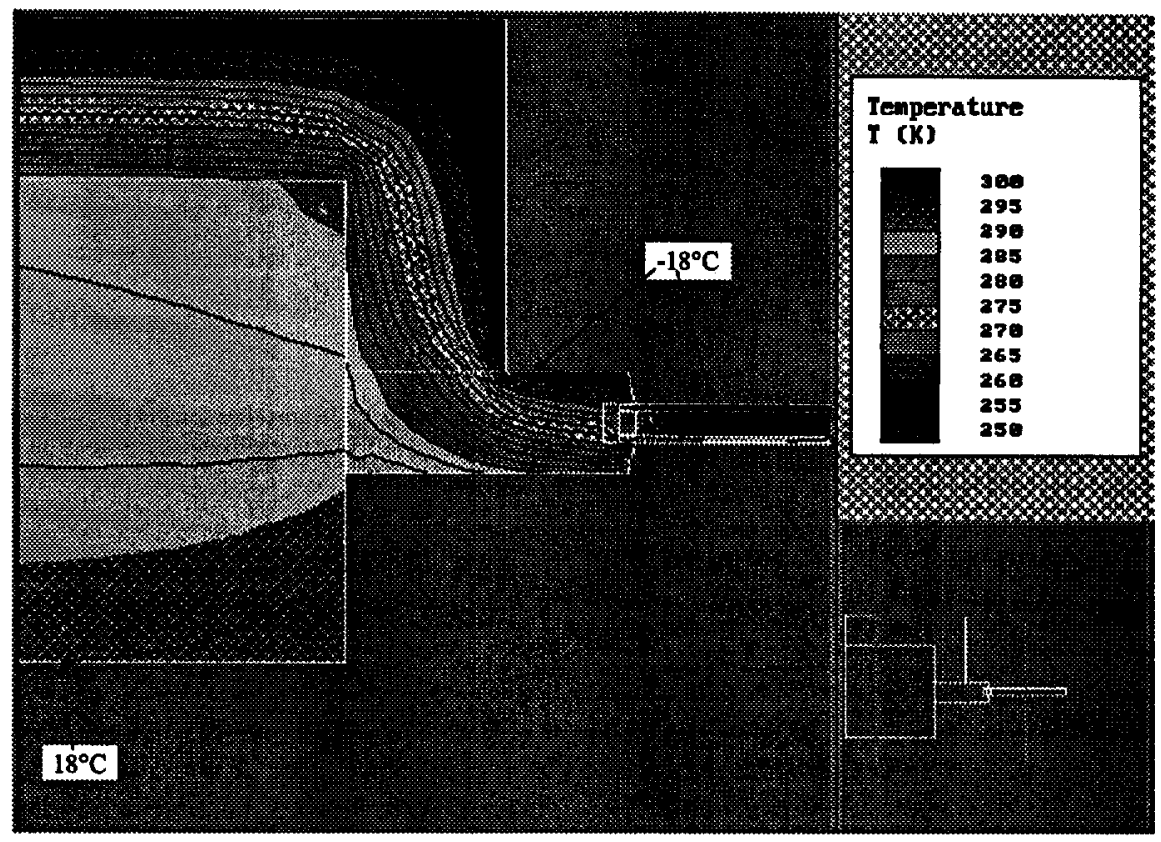

Fig. 5. Detail of Fig. 5.

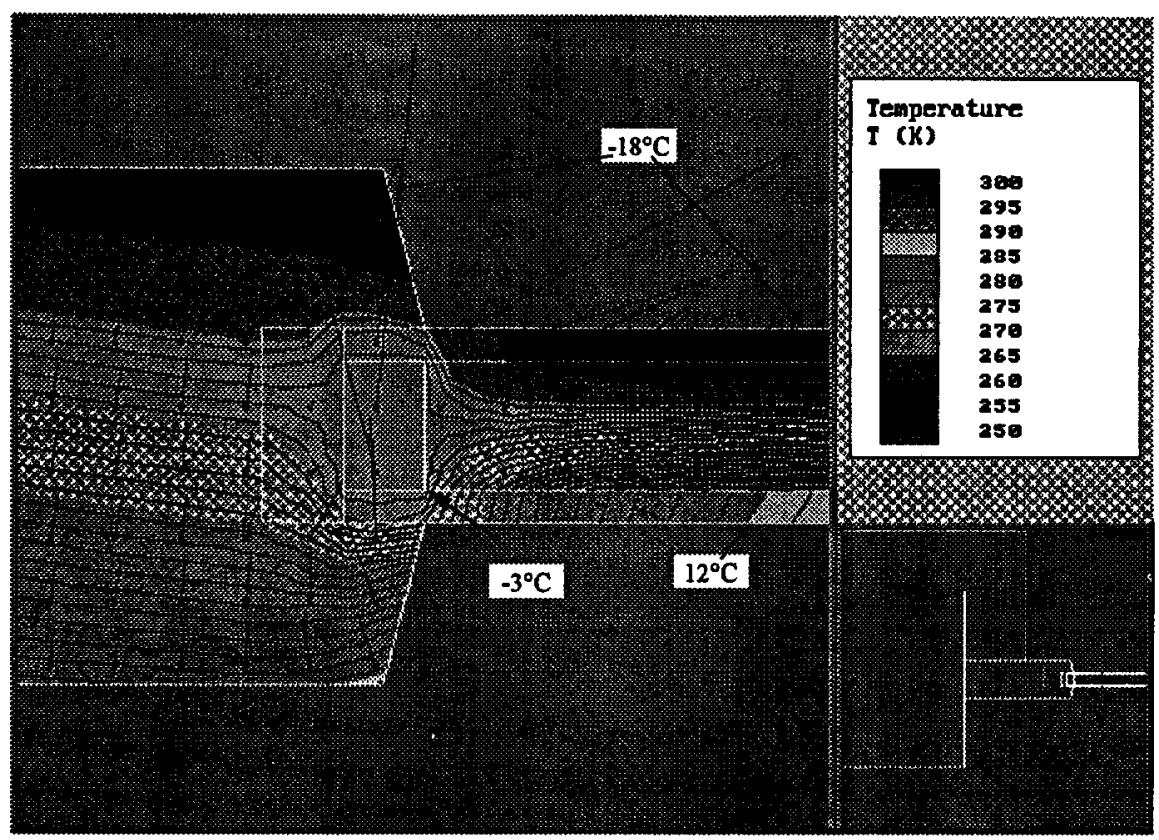

Fig. 6. Type I: usual window construction with wooden frame and aluminium spacer, brick or concrete wall well insulated.

another part due to the edge-seal and frame or attachment to the wall. For each of the windows a length-dependent heat flux coefficient $X_{\mathrm{E}}$ was calculated that gives the additional heat flux per unit length of the glazing edge and temperature difference. Departing from the proposed European standards, i.e. ISO DIS $10077 / \mathrm{prEN}$ 30077 (ISO, 1993), this heat flux coefficient includes the heat transfer caused by the
2D-effect of the spacer, the heat transfer through the frame and the heat loss through the edge of the wall. This method was chosen since all these details affect the total window $U$ value (see also Schultz and Thomsen (1990)). The length-dependent heat flux coefficient $X_{\mathrm{E}}$ has to be multiplied by the lengths of all edges and the temperature difference and added to the heat flux through the glazing. 


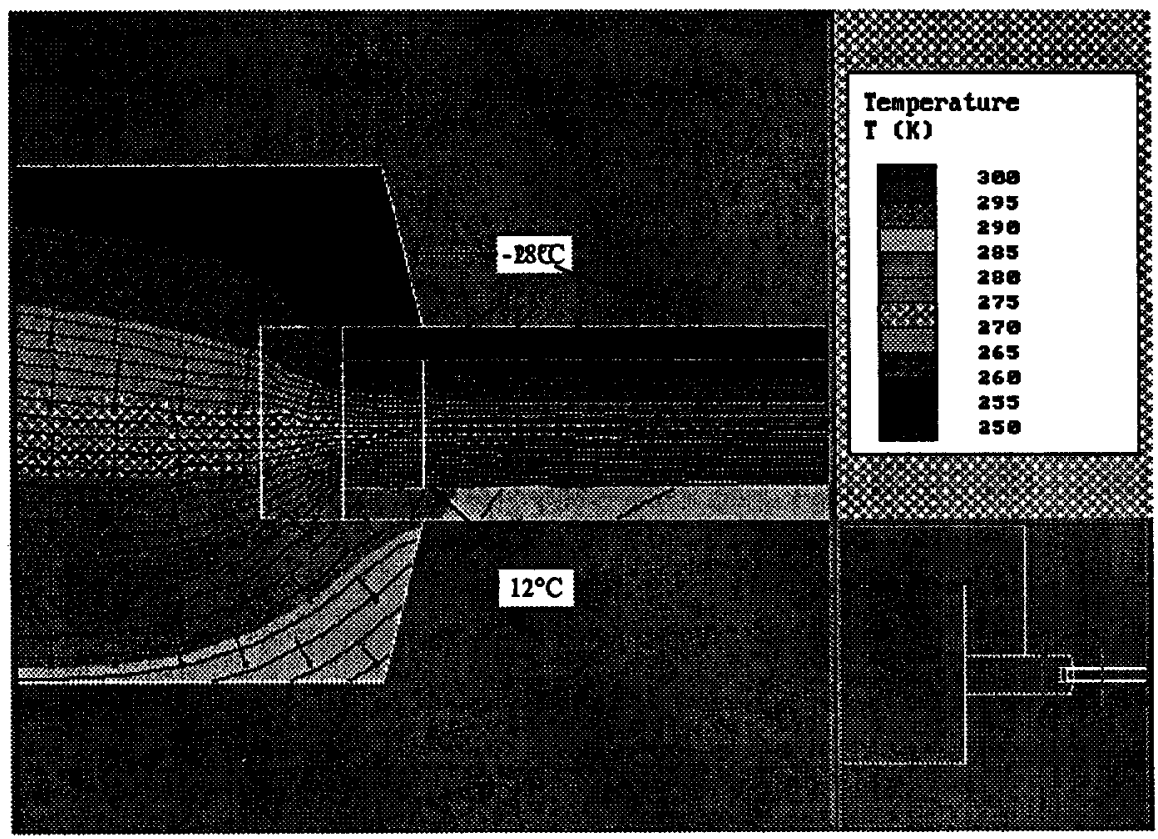

Fig. 7. Type II: the same construction as in Fig. 5, but with foamglass spacers.

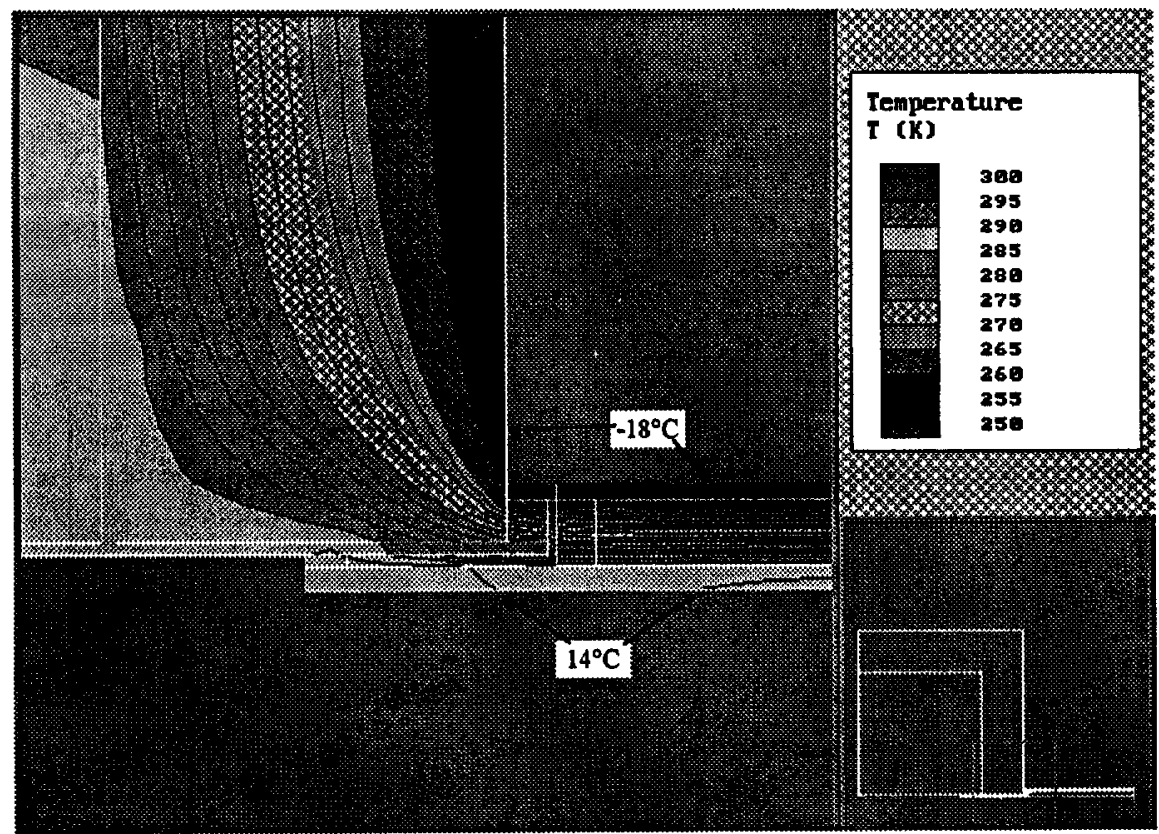

Fig. 8. Type III: frameless window integrated at the inner rim of a well insulated wall.

$$
\begin{gathered}
\Phi=A_{\mathrm{G}} U_{\mathrm{G}} \Delta T+\left(L X_{\mathrm{E}} \Delta T\right) \\
U_{\mathrm{tot}}=\frac{\Phi}{A_{\mathrm{tot}} \Delta T}
\end{gathered}
$$

Table 2 gives the length-dependent heat flux coefficient for the different types of window and the total window $U$ values for an example window with the transparent glazing area
$1 \mathrm{~m} \times 1 \mathrm{~m}$. In the values for the total heat flux $\Phi$ an estimate for the heat flux through the corners of each frame is included, derived from the $X_{\mathrm{E}}$ value.

For the average German climate, the German building code concerning the heat transfer through the building envelope (Wärmeschutzverordnung, 1994) suggests the calculation of an equivalent $U$ value $U_{\text {eq }}$ that takes into 


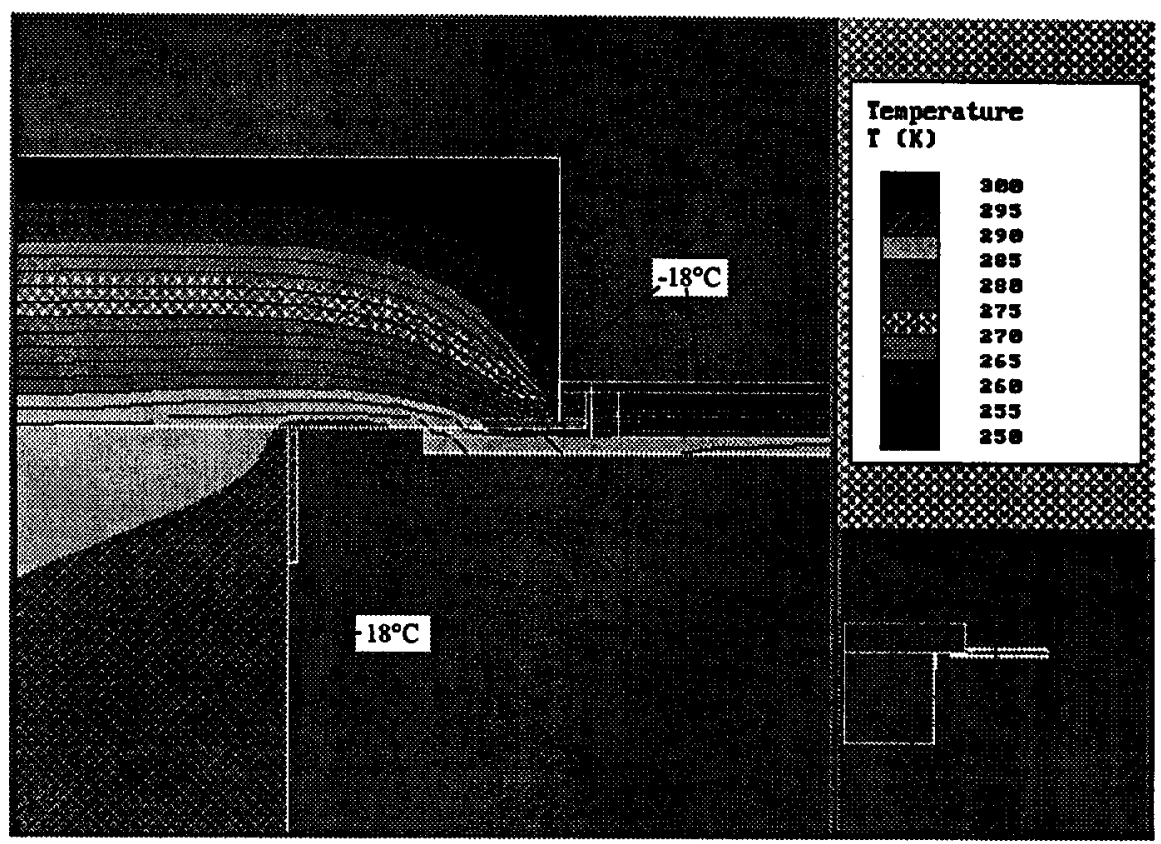

Fig. 9. Type IV: frameless window integrated at the outer rim of a well insulated wall.

account the yearly solar insolation on a given orientation. The $U_{\text {eq }}$ values for south-oriented windows are also given in Table 2. Negative values denote energy gain.

The results in Table 2 clearly show that solar energy gains that exceed the heat loss through the window can only be obtained with windows with an overall high thermal resistance.

Insulation glass units with foamglass spacers can also be used in solar cooking boxes and solar collectors, etc. Another application is a convective solar wall, a kind of trombe-wall, that is currently being developed in our Institute. For all these applications insulation glass units with the proposed high resistance edge-seal reduce energy loss and thus enhance the efficiency of the solar devices.

\section{OUTLOOK}

For now, the production of multiple glazing with the edge design presented can only be done by hand, because the existing industrial production lines demand a more stable spacer. This means that in glazings that are nowadays fixed together by hand, foamglass can be used without significant increase of costs. The production can be shifted to foamglass without great capital expenditure and time loss.

If the automated production of multiple

Table 2. Examples calculated with finite element analysis program ${ }^{\mathrm{a}}$

\begin{tabular}{|c|c|c|c|c|c|}
\hline & $X_{\mathrm{E}}(\mathrm{W} / \mathrm{m} \mathrm{K})^{\mathrm{b}}$ & $\Phi(\mathrm{W} / \mathrm{K})^{\mathrm{c}}$ & $A\left(\mathrm{~m}^{2}\right)^{\mathrm{d}}$ & $U\left(\mathrm{~W} / \mathrm{m}^{2} \mathrm{~K}\right)^{\mathrm{e}}$ & $U_{\text {eq }}\left(\mathrm{W} / \mathrm{m}^{2} \mathrm{~K}\right)^{\mathrm{f}}$ \\
\hline $\begin{array}{l}\text { Good standard design } \\
\text { Type I }\end{array}$ & 0.32 & $2.95(100 \%)$ & 1.85 & 1.60 & 0.11 \\
\hline $\begin{array}{l}\text { Good design } \\
\text { Type II }\end{array}$ & 0.25 & $2.30(78 \%)$ & 1.85 & 1.25 & -0.23 \\
\hline $\begin{array}{l}\text { Frameless window at inner rim } \\
\text { Type II }\end{array}$ & 0.16 & $1.86(63 \%)$ & 1.55 & 1.20 & -0.28 \\
\hline $\begin{array}{l}\text { Frameless at outer rim } \\
\text { Type IV }\end{array}$ & 0.11 & $1.61(55 \%)$ & 1.55 & 1.04 & -0.45 \\
\hline
\end{tabular}

a For an entire window with $1 \mathrm{~m} \times 1 \mathrm{~m}$ transparent glazing area, $U=1.1 \mathrm{~W} / \mathrm{m}^{2} \mathrm{~K}$, in a $30 \mathrm{~cm}$ stone wall with $10 \mathrm{~cm}$ insulation.

b Length-dependent heat flux coefficient for edge-seal, wooden frame and wall opening.

c Heat flux through the entire window per $1 \mathrm{~K}$ temperature difference.

d Area of rough wall opening.

- Average $U$ value for the wall opening.

${ }^{i}$ Equivalent $U$ value for south-oriented window; negative values denote energy gain. 
glazings is to be changed to using foamglass spacers, new production machines have to be constructed that solve the specific handling problems of foamglass, particularly of fragile foamglass sticks. Recently, the contact with an industrial company has been established to approach these difficulties. Investigation and construction of new machines mean a financial investment by the glass industry with the aim of increasing the production value.

Governmental institutions in different countries may help the industry to introduce the new technology through financial programmes of different aims (e.g. ecological or issues for energy saving). The new edge-seal and frameless window design can cause a drastic reduction of carbon dioxide emission by heating systems of buildings.

\section{CONCLUSIONS}

The design of the multiple glazing edge-seal presented, using thermally insulating foamglass as spacer material, has been investigated in different respects.

(1) The forces that occur on the spacer have been found to distribute evenly over the width of the spacer if the spacer is given a trapezoidshaped cross-section with a certain angle, so that triangular interstices for the sealant are formed. Thus, the stress occurring is minimized and kept well below the tensile strength of the foamglass. There is no need for a secondary seal connecting both panes directly and which would increase the heat transfer. The ideal angle depends on the dimensions of the glazing, i.e. the width and thickness of the panes and the interpane cavity.

(2) The comparison of the thermal performance of window assemblies using aluminium and foamglass as spacer materials yielded the result that the total window $U$ value can be reduced significantly. However, there are still limitations to the heat loss reduction due to the heat transfer through the window frame.

(3) The concept of frameless windows presented in this paper allows for further total window $U$ value reductions by omitting the frame and the heat transfer through it. Compared with common windows with a wooden frame and aluminium spacers (glazing area $1 \mathrm{~m}^{2}$, glazing $U$ value $1.1 \mathrm{~W} /\left(\mathrm{m}^{2} \mathrm{~K}\right)$, overall $U$ value $1.6 \mathrm{~W} /\left(\mathrm{m}^{2} \mathrm{~K}\right)$ over an area of $1.85 \mathrm{~m}^{2}$ ) the total window $U$ value for a glazing with the same characteristics and dimensions can be reduced to $1.04 \mathrm{~W} /\left(\mathrm{m}^{2} \mathrm{~K}\right)$ over an area of $1.55 \mathrm{~m}^{2}$. Thus, the total heat loss through a window of this size is reduced by $45 \%$. A comparison of the equivalent $U$ values of southoriented windows shows that for a common window of the same size the energy loss exceeds the solar energy gains $\left(U_{\mathrm{eq}}=0.11 \mathrm{~W} /\left(\mathrm{m}^{2} \mathrm{~K}\right)\right)$, whereas with a frameless window with foamglass spacers the solar energy gain is predominant $\left(U_{\text {eq }}=-0.45 \mathrm{~W} /\left(\mathrm{m}^{2} \mathrm{~K}\right)\right)$.

\section{REFERENCES}

Aschehoug O. and Baker J. (1995) Frame and edge-seal technology - an international review. In Window Innovations 1995, Conf. Proc., Toronto, Canada, June 5-6.

Bundesministerium für Bildung und Forschung (BMBF) (1996), Abschlußbericht BMBF Projekt $0329390 \mathrm{~A}$ und B, Hochwärmedämmende Isolierverbundsysteme, Bonn.

Canmet, S. S. and Fritzel, P. (1995) Spacers for highly insulating windows. In Window Innovations 1995, Conf. Proc., Toronto, Canada, June 5-6.

Van Dijk D. (1995) IEA Task 18; determination of key glass parameters; $U$-value. In Window Innovations 1995 , Conf. Proc., Toronto, Canada, June 5-6.

Elmahdy A. H. and Frank Th. (1993) Heat transfer at the edge of sealed insulating glass units: comparison of hot box measurements with finite-difference modeling. In ASHRAE Trans. 99 (1), 915-922.

Feist W. (1996) Fachdokumentation Nr. 3 Superfenster im Passivhaus, Passivhaus-Institut, Darmstadt, October.

Frank Th. and Ghazi Wakili K. (1995) Linear thermal transmittance of different spacer bars. In Window Innovations 1995, Conf. Proc., Toronto, Canada, June 5-6

Fraser R. A., de Abreu P. F., Wright J. L., Sullivan H. F. and Yao H. (1993) Critical issues in comparing edgeseal performance: modeling vs. experiment. In $A S H R A E$ Trans. 99 (1), 923-938.

Ghazi Wakili K. and Frank Th. (1993) Thermal conductivity measurements on glass, sealant and spacer materials using a symmetrically arranged heat flow meter apparatus, Document T18/B8/CH1/93, IEA Solar Heating and Cooling Programme Task 18, Duebendorf, Switzerland.

ISO/DIS 10077/prEN 30077 (1993) Windows, Doors and Shutters-Thermal Transmittance-Calculation Method.

Löffler M. (1995) Rahmenlose Fenster und Türen, In Glasverarbeitung 6/95, Coburg, pp. 65-67.

Löffler M. (1996) Schaumglas als Abstandhalter bei Mehrfachverglasungen, In Bauphysik 18 (1), 24-27.

McGowan A. G. (1995) Numerical prediction of window condensation potential. In ASHRAE Trans. 95 (1) 832-837.

Pittsburgh Corning Europe, Waterloo, Belgium, Foamglas Industrial Insulation Handbook (1992) product information of the Deutsche Pittsburgh Corning GmbH.

Quickfield student's version (1995) Tera Analysis, Tarzana, CA, U.S.A.

Reilly S. (1994) Spacer effects on edge-of-glass and frame heat transfer, In ASHRAE Trans. 100 (1) 1718-1804.

Schnell, W., Gross D. and Hauger W. (1985) Technische Mechanik, Vol. 2. SpringerVerlag, Berlin.

Schultz, J. M. and Thomsen, K. E. (1990) Thermal analysis of window design. In Building Physics in the Nordic Countries-Conf. Proc., August 20-22, Trondheim, Norway.

Sullivan H. F. and Wright J. L. (1995) Guarded heater plate 
measurements in support of warm-edge technology. In Window Innovations 1995, Conf. Proc., Toronto, Canada, June 5-6.

Wärmeschutzverordnung: Verordnung über einen energiesparenden Wärmeschutz in Gebäuden (1994) Government of the Federal Republic of Germany, Bonn.

Wright J. L., de Abreu P. F., Fraser R. A. and Sullivan
H. F. (1994) Heat transfer in glazing system edge-seals: calculations regarding various design options. In ASHRAE Trans. 100 (1), 1705-1717.

Wright J. L. and Sullivan H. F. (1989) Thermal resistance measurements of glazing system edge-seals and seal materials using a guarded heater plate apparatus. In ASHRAE Trans. 95 (2), 766-771. 